\title{
WORKING MOTHERS: FAMILY-WORK CONFLICT, JOB PERFORMANCE AND FAMILY/WORK VARIABLES
}

\author{
CYNTHIA J PATEL \\ patelc@ukzn.ac.za \\ VASANTHEE GOVENDER \\ ZUBEDA PARUK \\ SAROJINI RAMGOON \\ School of Psychology \\ University of KwaZulu-Natal (Howard College)
}

\begin{abstract}
The present study examined the relationship between family-work conflict, job performance and selected work and family characteristics in a sample of working mothers employed at a large retail organization. The hypothesis of a negative relationship between family-work conflict and job performance was rejected. Married women reported significantly higher family-work conflict than unmarried women, while women in the highest work category gained the highest job performance rating. More than half the sample indicated that paid work was more important than their housework and reported that their working had a positive impact on their families. The findings are discussed in relation to the changing work and family identities of non-career women.
\end{abstract}

Key words

Employed mothers, family-work conflict, job performance

The increasing number of women in the workforce is a global phenomenon and South Africa is no exception in this regard. Casale (2004) refers to this growth trend as the 'feminization' of the labour market. She notes that, whereas in 1995 about 38 percent of all women of working age were active in the work force, in 2001 nearly 51 percent of them were economically active. However, this increase has been in the lower paying categories, resulting in a larger percentage of women being concentrated in these categories in more recent years compared to the mid-nineties.

Casale and Posel (2002) contend that unlike other countries where women workers are being drawn into the labour market because of demand for female labour, in South Africa women are being forced to join the workforce, out of sheer economic need. They also observe that as a result of the increasing participation of women in "less secure" (p.1) work in the labour force, there has been an increase in the unemployment figures for women. While women form 43.8 percent of the workforce, they also comprise 52.3 percent of the unemployed (Gender Advocacy Project, 2003). With rising unemployment and scarcer employment opportunities, workers in low-level jobs are in the precarious situation of having to accept low salaries and ensure family survival or face unemployment and economic hardship. While these situations carry with them the potential for frustration and resentment, they could also offer opportunities for growth. Given their dire financial need and limited work options, employees are likely to be committed to their work and to strive for favourable work evaluations and promotion. This is especially true in industry, where worker commitment and performance are major contributors to the economic success of the company. In this work setting, it is in the interests of the employer to retain the best workers, and workers realize that failure to perform adequately may place them at risk for dismissal or replacement.

In traditional two-parent families, the father was seen as the family breadwinner while the mother was the nurturer and homemaker. These roles have evolved over the years with more women accepting the role of paid employment in their lives and men beginning to take on household and parenting duties (Pleck, 1993; Theunissen, van Vuuren \& Visser, 2003). For the growing number of single parent families (Robles, 1997), the concomitant increase in social and economic responsibilities is inevitable. The negative impact on the coping resources of single women is even greater (Verbrugge, 1993). According to Census96, there were almost 3.5 million female-headed households in South Africa (reported by Wallis \& Price, 2003).

Marsden, Kalleberg and Cook (1993) cite the distinction made by Hakim (1991) between two types of working women - one oriented toward a homemaker career and the other focused on work as a central goal. It is reasonable to assume that women in the first category may be less likely to pursue further education and training. If this group find themselves forced to join the workforce for economic reasons, they are likely to be employed in semi-skilled positions or jobs that require minimal training. The personal and economic realities that women face could result in a variety of role combinations, pointing to a shortcoming in Hakim's distinction. For example, it does not include those women who choose to work from home or are self-employed. In addition it does not mention the mother role - for both types of women, the mother role may or may not apply. Many women attempt to balance both roles and several models have been proposed which offer further insight into ways in which work and family roles interact. Wallis and Price (2003) describe three theories that are used in the literature:

a) Segmentation theory - work and family are seen as distinct domains in which individuals operate in terms of time, place, attitudes, feelings and behaviour. The basic assumption here is that since energy and time are limited, resources taken up in one role means that the other role is neglected. Greenhaus and Beutell's (1985) description of the work-family conflict as a form of inter-role conflict in which family and work demands are incompatible in some way is an example of this theory. 
b) Spillover theory - is based on the carry-over of attitudes from one role to another. People who are enthusiastic and committed in one role will carry over the same enthusiasm to the other role.

c) Compensation theory - if individuals are not satisfied in one role they will seek satisfaction in the other role.

In their review on role salience, Niles and Goodnough (1996) describe a study by Madill et al. (1988) in which 4 categories of employees (professional, managerial, clerical/sales and skilled/unskilled) are compared. The greatest difference in role salience between males and females was in the clerical/sales group with women placing more emphasis on home and family than on work. This suggests that there may be more ambivalence and stress arising out of the tension between work and family demands in this category of worker compared to the career woman. Netemeyer, Maxham and Pullig (2005) point out that the main shortcoming in their study on the work-family interface was the failure to measure the importance of family role versus the job role for employees. Eagle, Icenogle, Maes and Miles (1998) concluded from their review that workers report more work to family conflict than family to work conflict and that family boundaries are more permeable than work boundaries. In contrast, Spykerman (1997) opposed this contention in her review on gender roles and work, in which she concluded that family roles contribute more to role conflict than work roles. When financial need forces an individual to relinquish traditional roles and re-prioritise their values, workers are likely to become acutely aware of the need to keep interference resulting from family responsibilities at a minimum since, for the majority, a job means survival.

In general the work to family focus has attracted more research attention than the family to work influence (Burley, 1995; Carlson, 1999; Eagle et al., 1998).

Haar (2004) points out that the 'single direction' focus (work to family conflict or family to work conflict) is methodologically flawed. While some researchers have begun to recognize the bidirectional nature of work and family demands (Burley, 1995; Kinnunen \& Mauno, 1998), the review by Kossek and Ozeki (1998) shows that work-family measures that indicate the direction of role conflict perform better than measures that combine items measuring both directions. From a research point of view the work-family focus may be more appropriate for social inquiry, while the family-work focus may be more relevant to organizational stakeholders.

Among lower level workers the financial imperative is generally the most important reason for work. In addition when job insecurity is a reality, workers may hold on to their positions and increase the effort that they put into their work, thereby exacerbating family to work conflict (Kinnunen \& Mauno, 1998). The focus needs to shift away from ways in which work interferes with traditional parental and marital roles toward the threat of family pressures on work performance.

From industry's point of view, it would be reasonable to assume that employers are invested in retaining the best workers and in ensuring that performance is kept at an optimum level.

Eagle et al. (1998), referring to the American labour force, make the point that the retention of workers depends on suitable human resource practices. Employers, therefore, need to be able to recognize the role of family demands and devise appropriate ways of accommodating workers' needs and responsibilities in order to enhance work performance. According to Somers and Birnbaum (1998) this issue is neglected in research.

If, as Grzywacz, Almeida and McDonald, (2002) point out, structural features of the family, like parental and marital status, are likely to influence work and family dynamics, then it follows that working mothers may attempt to keep family to work conflict at a minimum so that their financial contribution to the family is not threatened. More specifically, Burke and Greenglass (2001) found that personal demographics predicted family to work conflict, while organizational stressors predict work to family conflict. Butler and Skattebo (2004) point out that since the parent role has stereotypically been associated with women, working mothers may be more prone to family-work conflict than working fathers. For working mothers therefore, it may be expected that the lower the interference from the family, the better the work performance.

Eagle et al. (1998) found that respondents with children reported significantly greater time-based family-work conflict than respondents without children. The number of children is said to be a good predictor of family to work conflict (Kinnunen \& Mauno, 1998) but not a reliable predictor of women's work performance (Campbell, Campbell \& Kennard, 1994). The latter found that mothers with younger children ( 5 and younger) obtained better work performance ratings than women with older children. They speculate that the women work harder to 'protect' their source of income as a result of their keen awareness of the financial contribution that they make and suggest that this argument would have greater support if the women's motivations for working were also known.

Since the family role has traditionally been seen as the central one for women, research on working mothers has tended to focus on the impact of work on the family, as more women take on the worker role (Simon, Kummerling \& Hasselhorn, 2004; Theunissen et al., 2003; Wallis \& Price, 2003). Frye and Breaugh (2004) point out that this trend has resulted in a better understanding of the work-family conflict than the family-work conflict. In addition, most studies (Brink \& de la Rey, 2001; Grzywacz et al., 2002; Theunissen et al., 2003; and those reported in Unger \& Crawford, 1992) have been conducted on professional women or women in high level positions and have tended to neglect women in lower paid positions.

\section{Aims of the study}

The present study was designed as an exploratory investigation of the relationship between family-work conflict and job performance rating in a sample of working mothers in a retail institution.

\section{Hypothesis}

There is a negative relationship between family-work conflict and job performance

Secondary aims included an examination of several demographic variables, family variables and work issues in relation to family-work conflict and job performance rating

\section{RESEARCH DESIGN}

\section{Research approach}

An exploratory survey design using questionnaires and scales was employed.

\section{Participants}

Of a total number of 123 working mothers employed on a full time basis at a large retail organization in Durban, South Africa, 100 women participated in the study. The racial breakdown was as follows: 48 were Black, 35 were Indian, 16 were Coloured and one was White. Twenty women were 30 years of age or below, 27 were between 31 and 40 years old, 35 were between 41 and 50 years, and 18 were over 50 years. Sixty-seven of the participants were married and 33 were not, while 61 lived in a nuclear (consisting of father, mother and children) family and 39 lived within an extended family system. With regard to educational level, 17 had a primary school education, 78 had secondary education and five had a tertiary level of education. The mean 
length of service (including broken service) was 11.04 years. All the women that had left work at some stage in their work lives $(n=86)$ reported that they were forced to return to work for purely financial reasons.

Category One workers included till packers and service area assistants, Categories Two and Three were clerical staff and cashiers respectively, while Category Four was made up supervisors.

\section{Measuring Instruments}

Four sets of measures were obtained. These were:

a) A biographical questionnaire, including age, educational level, marital status and number of children.

b) The Family to Work Conflict Questionnaire as used by Eagle, Miles \& Icenogle (1997). It was made up of items taken from three separate instruments developed by Frone, Russell and Cooper (1992), Gutek, Searle and Klepa (1991) and Wiley (1987), all cited in Eagle et al. Internal consistency estimates of reliability for the three scales were 0,$78 ; 0,81$ and 0,85 respectively. The thirteen-item instrument used a 5-point Likert Scale response format (coded such that $1=$ strongly disagree to $5=$ strongly agree). The possible scores ranged from 13 to 65: the higher the score, the higher the family to work conflict.

c) A set of questions measuring family and work issues, developed by the first two authors of the present study, included the following:

- Work category (with 1 indicating the lowest, and 4 indicating the highest work category)

- Did you start work pre/post marriage?

- Do you think you would be a better mother if not working (yes/no)?

- Number of years of service.

- Which is more important to you (paid work/house work)?

- Given a choice, would you continue working (yes/no)?

- What is your preference (paid work/house work)?

- How do you perceive the influence of work on your life (positive /negative)?

d) A Job Performance Rating (JPR) developed by the retail organization from which the sample was drawn, included such issues as punctuality, ability to handle pressure, systematic worker, customer service, respect/collegiality. There were ten items in all and each participant was rated on a scale from 1 to 10 , with scores between 1 and 3 reflecting 'poor' performance, scores between 4 and 6 'average', and between 7 and 10, 'very good' to 'excellent'. The range of possible scores was 10 to 100 .

\section{Procedure}

Permission for the study was obtained from the Human Resources division of the retail organization where the study was conducted. The purpose of the study, along with issues of confidentiality and anonymity, were explained to the employees at a staff meeting. The questionnaires were then distributed to those who consented to participate, and were completed during their break in the presence of the second author who responded to any queries.

Participants' immediate supervisors, who were requested to sign consent/confidentiality forms prior to the assessments, completed the job performance ratings.

\section{RESULTS}

The Statistical Package for the Social Sciences (SPSS) for Windows Version 11.0 was used to analyse the data. The analytic options in this study were somewhat restricted as a result of the small sample. The Pearson $r$ was used to test the main hypothesis of a relationship between family-work conflict and job performance. Ideally, factorial analysis of variance techniques should have been employed to analyse group differences.
However, given the small sample size, separate one-way anovas and t-tests were used. The latter were used to examine differences between groups on the dependent variables, namely, job performance and family-work conflict. Post hoc analysis, using the Scheffé Test, was conducted to locate significant differences where more than two groups were involved. It must be pointed out that more meaningful insights, for example interactions among variables, were compromised in the process.

Descriptive statistics including percentages, means, standard deviations, and chi-square analyses (for categorical data) were also used.

TABLE 1

MEANS, STANDARD DEVIATIONS, INTER-CORRELATION OF MEASURES AND Alpha COEFficients on the diagonal

\begin{tabular}{lcccc}
\hline & Mean & SD & 1 & 2 \\
\hline 1. Job Performance Rating (JPR) & 54,03 & 11,67 & $(0,90)$ & \\
2. Family-Work Conflict (FWC) & 27,86 & 12,71 & 0,15 & $(0,97)$ \\
\hline
\end{tabular}

For both the Job Performance Rating (JPR) and Family-Work Conflict (FWC) Scales the alpha coefficients were 0,90 and 0,97 respectively, indicating excellent inter-item consistency. With the Job Performance Rating having a possible score range of 10 to 100 , the mean score for the sample was 54,03 , with 7 percent of the respondents scoring under 40,68 percent scoring between 40 and 60, 21 percent between 61 and 70 and just 4 percent of the respondents obtaining ratings over 70 .

The Family-Work Conflict Scale, having a possible score range of 13 to 65 , yielded rather low scores with a mean of 27,86 . Sixtyseven percent of the sample obtained scores below 30 on the scale, indicating low family to work conflict, 33 percent of the scores were evenly spread between 31 and 50 and just 6 percent received scores over 50 .

The Pearson $r$ was used to calculate the relationship between job performance and family-work conflict, as well as with the other continuous variables, age and years of service. While the relationship between the two main variables was found to be positive, rather than negative as expected, this value was not significant. Of the other relationships, only age and job performance rating was found to be significant $(r=0,20 ; p<0,05)$, indicating that the older the worker, the better the job performance rating.

The following tables contain results of the analyses from the comparisons of means (for the variables job performance rating and family-work conflict) and the frequencies for the categorical data collected on family and work issues.

TABLE 2

One WAy AnOVA fOr JOB PERFormance RATING (JPR) $\times$ EDUCATION

\begin{tabular}{|c|c|c|c|c|}
\hline & & MEANS (SD) & & F \\
\hline & Primary & Secondary & Tertiary & \\
\hline JPR & $49,41(8,55)$ & $54,42(11,47)$ & $63,60(18,41)$ & 3,19 * \\
\hline
\end{tabular}

${ }^{*} \mathrm{p}<0.05$

The above table shows that workers with higher education received better job performance ratings than those with lower education. Post-hoc analyses (Scheffé Test) revealed that the tertiary educated sample was assigned significantly higher performance ratings than the sample with primary education. These results need to be treated with caution because of the small sample size and large variance in the former group. 
TABLE 3

One way Anova for Job performance rating (JPR), FamilyWORK CONFLICT $($ FWC) $\times$ WORK CATEGORY $($ WC)

\begin{tabular}{ccccc}
\hline \multicolumn{4}{c}{ MEANS (SD) } & F \\
\hline WC1 & WC2\&3 & WC4 \\
JPR & $50,88(9,16)$ & $58,66(14,34)$ & $56,42(10,38)$ & $5,22^{* *}$ \\
FWC & $23,84(10,73)$ & $30,50(13,34)$ & $39,58(11,15)$ & $10,19^{* * *}$ \\
\hline
\end{tabular}

${ }^{* *} \mathrm{p}<0.01$

$* * * \mathrm{p}<0.001$

Since there were only two workers in Category Two, they were combined with Category Three.

With regard to job performance rating, comparison of the means indicated that there were significant differences between the different work categories with Category Three (cashiers, sales staff and clerks) receiving the highest ratings. Post hoc analyses revealed that there were significant differences between the lowest, Category One (till packers and service area assistants) and middle, Category Three (cashiers, sales staff and clerks), with the latter receiving more positive evaluations than the former.

On family-work conflict, there were significant differences in the family to work conflict reported between the different categories. The Scheffé test indicated that the main difference lay between the highest, Category Four (supervisors) and lowest, Category One ( $\mathrm{p}<0,001)$. The supervisors revealed more family to work conflict than the till packers and service area assistants. The middle category also had significantly higher family-work conflict scores than the lowest level workers $(\mathrm{p}<0,05)$.

\section{TABLE 4}

T-TEST ON SELECT FAMILY VARIABLES AND FAMILY-WORK CONFLICT

\begin{tabular}{|c|c|c|c|}
\hline & Mean & SD & $t$ \\
\hline \multicolumn{4}{|l|}{ Marital Status } \\
\hline Married $(\mathrm{n}=67)$ & 30,52 & 12,96 & \\
\hline Not married $(n=33)$ & 22,45 & 10,41 & 3,35 ** * \\
\hline \multicolumn{4}{|l|}{ Better Mother (if not working) } \\
\hline Yes $(n=45)$ & 25,82 & 12,59 & \\
\hline No $(n=55)$ & 29,53 & 12,68 & $-1,46$ \\
\hline \multicolumn{4}{|l|}{ Work influence (on family) } \\
\hline Positive $(n=56)$ & 29,59 & 12,57 & \\
\hline Negative $(n=44)$ & 25,66 & 12,69 & 1,55 \\
\hline
\end{tabular}

$* * * p<0.001$

Of the family variables, the married women experienced significantly more family to work conflict than those women who were not married. Interestingly, those women who said they would be better mothers if they did not work reported lower (though not significantly so) family to work conflict than those who said that they would not. Similarly, those who reported that their working had a negative influence on family had lower family to work conflict than those who reported positive influences.

Table 5 indicates a significant relationship between the womens' perceived work influence on family and their perception of themselves as mothers if they were not working. Almost all mothers who reported that their working had positive influences on the family also said that they did not feel they would have been better mothers if they were not working. All those who reported negative influences on family, said they would have been better mothers if they were not working.
TABLE 5

CHI-SOUARE ANALYSIS OF 'WORK INFLUENCE' x 'BETTER MOTHER'

\begin{tabular}{|c|c|c|c|}
\hline & \multicolumn{2}{|c|}{ Work influence } & \multirow[t]{2}{*}{ Chi square } \\
\hline & Positive & Negative & \\
\hline \multicolumn{4}{|l|}{ Better mother } \\
\hline Yes & 1 & 44 & $96,03 * * *$ \\
\hline No & 55 & 0 & \\
\hline
\end{tabular}

TABLE 6

CHI-SQUARE ANALYSIS OF 'WORK CATEGORY' $\times$ 'WORK INFLUENCE'

\begin{tabular}{rcccc}
\hline & WC1 & WC2\&3 & WC4 & Chi-square \\
\hline Work influence & & & & \\
Positive & 33 & 13 & 10 & $6,90^{*}$ \\
Negative & 23 & 19 & 2 & \\
\hline
\end{tabular}

${ }^{*} \mathrm{p}<0,05$

The chi-square analysis revealed a significant relationship between work category and mothers' perception of the impact of work on the family. Fifty-nine percent of the lowest category workers and 83 percent of the highest category workers reported that their working had a positive impact on their families. Almost 60 percent of the middle category felt that working had a negative impact on family.

TABLE 7

CHI-SQUARE ANALYSIS OF 'IMPORTANCE OF HOUSE VS PAID WORK' $\times$ 'DECISION GIVEN CHOICE'

\begin{tabular}{|c|c|c|c|}
\hline Importance of: & Housework & Paid work & Chi square \\
\hline \multicolumn{4}{|l|}{ Decision given choice } \\
\hline Continue working & $14(15,7 \%)$ & $55(61,8 \%)$ & 1,86 (ns) \\
\hline Stay home & $7(7,9 \%)$ & $13(14,6 \%)$ & \\
\hline
\end{tabular}

Chi-square analysis did not yield a significant relationship between 'Importance of house versus paid work' and 'Decision given choice'. In the latter case they were asked if they would continue working if they were given a choice. As expected, of the 68 participants who said paid work was more important, almost 81 per cent said that they would continue working if given the choice. The remaining 11 respondents who rated both housework and paid work as equally important were omitted from the analysis because of the small number.

\section{DISCUSSION}

The socialisation of women from childhood into accepting home maker and nurturer roles and giving these precedence over work roles is an issue that has occupied the minds of social researchers for decades. Whilst labour legislation has supported the involvement of women in the work place, with the introduction of equity laws and paid maternity leave intended to lure women back to the work place after having children, the real tension lies with working mothers. They continue to receive the message from society that they should curb their work involvement in order to minimize the impact of their jobs on their family lives (Butler \& Skattebo, 2004; Eagle et al., 1998). At the same time it is expected that 
economic and work pressures should demand minimal, if any, interference from family. Garey (1995) highlights the dilemma by pointing out that the term 'working mother' fuses the individual concepts worker and mother, each of which have different and opposing societal expectations. Women are therefore faced with reconciling this apparent incompatibility, resulting in inter-role conflict (Eagle et al., 1997). Since the family role has traditionally been seen as central to a woman's identity, working mothers are usually seen as more likely to experience stress when attempting to juggle work and family demands (Eagle et al., 1998) and more likely to allow family to interfere with work responsibilities.

Contrary to expectations, the hypothesized negative relationship between family-work conflict and work performance was not found in this sample of working mothers. In an experimental study by Butler and Skattebo (2004), the experience of family-work conflict had no effect on performance ratings given to female workers, yet men with conflicts were assigned lower ratings. Instead, in this study a weak positive correlation was found. Although the association was not significant, there appeared to be a slight tendency for those who reported greater family to work conflict to obtain better job performance ratings. In line with the Campbell et al. (1994) explanation, it may be the case that the women in the present study work hard, and do not allow family demands to impact on their work performance as expected, because they are very aware of the financial implications of the work role.

According to Greenhaus and Powell (2003), family-work conflict is likely to impact on work performance when family demands are high and when pressure to participate in the work domain is low. For this sample, the opposite may be true, with work pressure being stronger than family pressures, resulting in a weak family-work conflict and job performance link. Moreover, Noor (2004) suggests that women are becoming more involved and committed to work and this may be a factor in their handling of work and family roles. Approximately two thirds of the sample indicated the importance of paid work over housework, with about the same number choosing to continue working if given the choice. Somers and Birnbaum's (1998) finding that career commitment was positively related to job performance in their sample (87 percent of which were women) of hospital employees provides further support for this.

While the job performance ratings appeared to be normally distributed, the majority of the women obtained low scores on the Family-Work Conflict Scale, resulting in a positively skewed distribution. This finding could be accepted at face value and as Grzywacz et al. (2002) suggest, these working mothers were attempting to keep family to work conflict at a minimum so as not to threaten their financial contribution to the family. Alternatively, the women may have been inclined to underreport the effects of their family responsibilities on their work, because the study was conducted at their place of employment.

On the job performance ratings, significant relationships were obtained between education, age and work category variables. In the absence of research on these issues in relation to job performance and the limited sample size, the following interpretations remain speculative at best.

Education was associated with higher job performance ratings, with women having tertiary education being assigned significantly higher performance ratings than those with primary education. This may be related to the fact that women with higher education are more likely to have career aspirations, have an intrinsic interest in their work and therefore invest more in their jobs, resulting in higher performance ratings compared to women with lower education whose involvement in the work place may be driven by purely monetary gains. Women in the former group are also likely to have higher feelings of self-efficacy, which could translate into better work performance.

Another significant finding was that the older the worker, the better her job performance rating. It is possible that the older the worker, the longer the years of service and the more experience resulting in better work performances.

The middle category (cashiers) workers received significantly higher evaluations on job performance, than the lowest category (till packers and service area assistants). Perhaps this can be ascribed to the former group feeling that they can aspire to promotion to the next level whereas, for the lowest level workers, promotion to the highest category seems too distant. In addition, the nature of the work done by cashiers allows for more interaction with customers, providing the opportunity to engage in service-oriented tasks, thereby creating a better impression of their work performance.

Family-work conflict scores also differed by work category, with the highest conflict scores recorded by supervisors, cashiers next and finally packers with the lowest scores. Significant differences were found between till packers and both cashiers and supervisors. The greater responsibilities and demands at the workplace may be reflected in these senior workers experiencing their family demands as affecting their work commitments. They may also be expected to take work home and may perceive their family responsibilities as an obstacle to the completion of their work tasks.

Supervisors, who were more senior, and possibly more secure in their jobs than the lower category workers, may also have felt safer to report higher family to work conflict rather than minimizing it compared to the lower category of workers.

Although more than half of the sample reported positive influences on the family, the breakdown by worker category yielded some interesting findings. Although the supervisors (Category Four) experienced the highest FWC, 10 of the 12 in the group indicated that their working had a positive impact on their families. Surprisingly almost 60 percent of the Category One workers reported positive influences and 60 percent of Category Three workers reported negative influences. This finding may be explained by women in Category One regarding 'positive influence' on their families in terms of the financial contribution they were able to make to their homes, while women in the supervisor category (Category Four) may have associated the term with notions of independence, providing positive role models and being in a position to offer a better quality of life to their families.

Further investigation of the middle category (who reported a negative impact) revealed that $75 \%$ of them were married. In fact higher family-work conflict scores were found among the married women compared to the single women. It is very likely that the family interference with work for this middle group refers to marital discord and their working is seen as having a negative influence on the family. Adams, King and King (1996) also report that family-work conflict was found to decrease marital satisfaction. This may testify to society's expectation that women should find it acceptable to allow family responsibilities to intrude on their work but not vice versa.

It has been suggested that differences between husbands' and wives' perceptions of women working often contribute to conflict (Lupton \& Schmied, 2002; Spurlock, 1995). It may be the case that husbands become resentful of their additional family and household responsibilities as a result of their wives working and/or that their traditional role as breadwinner is threatened, leading to marital strain. Women in this group then see their working as having a negative influence on family. 
Unlike Kinnunen and Mauno's (1998) finding, in the present study the number of children was not related to family-work conflict or to job performance rating.

The finding that more than half the sample reported positive influences of their jobs on family and that 68 percent regarded paid work as more important than housework is an acknowledgement of the growing financial contributions that women are making to their homes. Whilst in the past, working women complemented their partners' income, women's financial contributions are increasingly representing an integral if not sole source of income for many families. This is further supported by the finding that while more than 80 percent said they were forced to work for financial reasons (after a break in service), it may be the case that after experiencing first hand the emotional and social rewards of work, about the same number indicated that they would continue working rather than stay at home.

Moreover, the finding that more than half the sample did not think they would be better mothers if they stayed at home, acknowledges the growing number of women who resist the traditional roles foisted upon them by society and who no longer define their identities purely in terms of these roles. Loscocco's (1997) interviews with self employed men and women indicated that they often spoke about breadwinning and nurturing in the same breath. This suggests that the good provider and good mother roles that were traditionally used to distinguish between fathers and mothers need to be re-examined since a blurring of the two identities seems to be occurring. This speaks to the need to recognize the growing involvement of women in the work place as more than just a hobby or temporary distraction from their 'more important' roles in the home. It may also mean that the work role serves to enhance their identities, forcing a re-examination of the conflict hypothesis and lending support to the critique around role salience. It also recognizes the need to remove the burden of minimizing the spillover effect from family to work for women and making it a concern of all the stakeholders involved. While these interpretations are offered with a degree of caution, it must be remembered that the possibility of social desirability cannot be ignored given that the questionnaires were completed in the work environment. It may be the case that, although anonymity was assured, the women might have been reluctant to admit the extent to which family impacted on their work responsibilities.

The general picture that appears to be emerging though, is that, contrary to expectations, these women report low family to work conflict, they report positive effects on family with 80 percent indicating they would continue working if they were given a choice.

One of the major shortcomings of this study is the small sample size, which limits the use of more advanced statistical analyses. In addition, this study assumed that family roles were important to these women and instead chose to ask about the (paid) work role in relation to the (unpaid) housework role. We could have asked them to rate the different roles in order of importance. Future research should heed the suggestion of Cinamon and Rich (2002) that we first identify people in terms of the importance they attach to work and family roles and then examine its relation to levels of work-family conflict.

\section{REFERENCES}

Adams, A.G., King, L.A. \& King, D.W. (1996). Relationships of job and family involvement, family social support, and workfamily conflict with job and life satisfaction. Journal of Applied Psychology, 81 (4), 411-420.

Brink, B. \& de la Rey, C. (2001). Work-family interaction strain coping strategies used by successful women in the public, corporate and self-employed sectors of the economy. South African Journal of Psychology, 31 (4), 55-61.
Burke, R.J. \& Greenglass, E.R. (2001). Hospital restructuring, work-family conflict and psychological burnout among nursing staff. Psychology and Health, 16, 583-594.

Burley, K.A. (1995). Family variables as mediators of the relationship between work-family conflict and marital adjustment among dual-career men and women. Journal of Social Psychology, 135 (4), 483-497.

Butler, A.B. \& Skattebo, A. (2004). What is acceptable for women may not be for men: The effect of family conflicts with work on job-performance ratings. Journal of Occupational and Organisational Psychology, 77, 553-564.

Campbell, D.J., Campbell, K.M., \& Kennard, D. (1994). The effects of family responsibilities on the work commitment and job performance of non-professional women. Journal of Occupational and Organisational Psychology, 67, 283-296.

Carlson, D.S. (1999). Personality and role variables as predictors of three forms of work-family conflict. Journal of Vocational Behaviour, 55, 236-253.

Casale, D. (2004). What has the feminisation of the labour market 'bought' women in South Africa? Trends in labour force participation, employment and earnings, 1995-2001. Development Policy Research Unit, Working paper 04/84.

Casale, D. \& Posel, D. (2002). The continued feminisation of the labour force in South Africa: An analysis of recent data and trends. The South African Journal of Economics, 70 (1), 156-184

Cinamon, R.G. \& Rich, Y. (2002). Profiles of attribution of importance to life roles and their implications for the work-family conflict. Journal of Counseling Psychology, 49 (2), 212-220.

Eagle, B.W., Icenogle, M.L., Maes, J.D. \& Miles, E.W. (1998). The importance of employee demographic profiles for understanding experiences of work-family inter-role conflicts. The Journal of Social Psychology, 138 (6), 690-709.

Eagle, B.W., Miles, E.W. \& Icenogle, M.L. (1997). Inter-role conflict and the permeability of work and family domains: Are there gender differences? Journal of Vocational Behaviour, $50,168-184$.

Frye, N. K. \& Breaugh, J.A. (2004). Family-friendly policies, supervisor support, work-family conflict, family-work conflict, and satisfaction: A test of a conceptual model. Journal of Business and Psychology, 19 (2), 197-220.

Garey, A. I. (1995). Constructing motherhood on the night shift: "Working mothers" as "Stay-at-home moms". Qualitative Sociology, 18 (4), 415-437.

Gender Advocacy Project (2003). Retrieved July 5, 2005, from the World Wide Web: http://www.genderstats.org.za

Greenhaus, J.H. \& Beutell, N.J. (1985). Sources of conflict between work and family roles. Academy of Management Review, 10, 76-88.

Greenhaus, J.H. \& Powell, G.N. (2003) When work and family collide: Deciding between competing role demands. Organisational Behaviour and Human Decision Processes, 90 (2), 291-303.

Grzywacz, J.G., Almeida, D.M. \& McDonald, D.A. (2002). Workfamily spillover and daily reports of work and family stress in the adult labor force. Family Relations, 51, 28-36.

Haar, J.M. (2004). Work-family conflict and turnover intention: Exploring the moderation effects of perceived work-family support. New Zealand Journal of Psychology, 33 (1), 35-39.

Kinnunen, U. \& Mauno, S. (1998). Antecedents and outcomes of work-family conflict among employed women and men in Finland. Human Relations, 51 (2), 157-176.

Kossek, E.E. \& Ozeki, C. (1998). Work-family conflict, policies, and the job-life satisfaction relationship: A review and directions for organizational behavior-human resources research. Journal of Applied Psychology, 83 (2), 139-149.

Loscocco, K.A. (1997). Work-family linkages among selfemployed women and men. Journal of Vocational Behaviour 50, 204-226.

Lupton, D. \& Schmied, V. (2002). "The right way of doing it all": First-time Australian mothers' decisions about paid employment. Women's Studies International Forum, 25 (1), 97-107. 
Marsden, P.V., Kalleberg, A.L. \& Cook, C.R. (1993). Gender differences in organizational commitment: Influences of work positions and family roles. Work and Occupations, 20 (3), 368-390.

Netemeyer, R.G., Maxham, J.G. \& Pullig, C. (2005). Conflicts in the work-family interface: Links to job stress, customer service employee performance, and customer purchase intent. Journal of Marketing, 69, 130-143.

Niles, S.G. \& Goodnough, G.E. (1996). Life-role salience and values: A review of recent research. The Career Development Quarterly, 45, 65-86.

Noor, N.M. (2004). Work-family conflict, work- and family-role salience, and women's well being. The Journal of Social Psychology, 144 (4), 389-405.

Pleck, J.H. (1993). Are "family supportive" employer policies relevant to men? In J.C. Hood (Ed.). Men, work and family. Newbury Park, CA: Sage.

Robles, B.J. (1997). An economic profile of women in the United States. In E Higginbotham \& M. Romero (Eds.). Women and work: Exploring race, ethnicity and class. Thousand Oaks: Sage.

Simon, M., Kummerling, A. \& Hasselhorn, H-M. (2004). Workhome conflict in the European nursing profession. International Journal of Occupational and Environmental Health, 10 (4), 384-391.
Somers, M.J. \& Birnbaum, D. (1998). Work-related commitment and job performance: It's also the nature of the performance that counts. Journal of Organisational Behaviour, 19, 621-634.

Spykerman, S. (1997). Gender roles and work: Recent research. Retrieved July 5, 2005, from the World Wide Web: http://www.hope.edu/academic/psychology/335/webrep/ge nroles.htm

SPSS (2002). Statistical package for the social sciences. Version 11. Chicago: SPSS Inc.

Spurlock, J. (1995). Multiple roles of women and role strains. Health Care for Women International, 16, 501-508

Theunissen, B., van Vuuren, L.J. \& Visser, D. (2003). Communication of job-related information and work-family conflict in dual-career couples. South African Journal of Industrial Psychology, 29 (1), 18-25.

Unger, R. \& Crawford, M. (1992). Women and Gender: A feminist psychology. New York: McGraw Hill.

Verbrugge, L.M. (1993). Marriage matters: Young women's health. In B.C. Long \& S.E. Kahn (Eds.). Women, work and coping. Montreal \& Kingston: McGill-Queens University Press.

Wallis, T. \& Price, L. (2003). The relationship between workfamily conflict and central life interests amongst single working mothers. South African Journal of Industrial Psychology, 29 (1), 26-31. 